\title{
South Africa, the Arts, and Youth In Conflict With the Law
}

\author{
Sheila C. Woodward, Julia Sloth-Nielsen, \& Vuyisile Mathiti
}

This paper describes the DIME (Diversion into Music Education) youth intervention program that originated in South Africa in 2001. DIME offers instruction in African marimba and djembe bands to juvenile offenders. Conceived as a community collaboration among organizations in the cities of Cape Town, SA and Tampa, USA (including the University of the Western Cape and the University of South Florida), DIME offers a unique example of community music and multicultural music education.

In the 1980s, the world focused on people fighting against apartheid in South Africa. These people included many children and teenagers who were arrested and jailed, often without trial. Even worse, many children were held in adult prisons.

When South Africa achieved democratic rule in 1994, a new system began to evolve for children in conflict with the law. At the same time, non-governmental organizations concerned with youth crime began experimenting with non-residential "life skills programs" (or "diversion programs") as alternatives to prosecution and incarceration. As a result, alternative programs for young offenders have grown dramatically since 1994 (Sloth-Nielsen, 2001).

The major impetus for this growth in alternative programs came from non-governmental and voluntary agencies. Having formed co-operative relationships with courts and prosecutors, these agencies channeled children away from the formal justice system. In return for the eventual withdrawal of charges, these agencies guaranteed that young offenders would satisfactorily complete "diversion programs." These diversion programs have come to be used as pre-trial options, obviating the need for court appearances and criminal trials (Sloth-Nielsen, 2003). The legal mechanism that permitted the use of diversion programs was the prosecutors' discretion to withdraw charges. Magistrates and judges have generally played a limited role in the referral of children to diversion programs. The benefits of diversion over criminal prosecution and trial are clear:

- Children avoid detention in police custody where they often come into contact with gangs and hardened criminals

- Court time is saved because prosecutors usually withdraw cases from the court roll on condition that young offenders comply with the requirements of diversion programs

- Children avoid the negative effects of a criminal record, which can brand them for life and impair their chances of obtaining employment 
- During diversion programs, children spend their time learning life skills, rather than wasting their time in the fruitless exercises of being tried, convicted, and sentenced (all too often, convictions involve conditionally suspended sentences)

- Longitudinal studies appear to show that diversion is effective in preventing recidivism. Some of the more established programs have been subjected to evaluation, with extremely positive results. A major follow-up study relating to 600 children who had participated in the life skills program in the mid $1990 \mathrm{~s}$ revealed that the re-offending rate of participating children was less than $6 \%$. This study also found a high rate of content retention from the program among the children and reported that the intervention had improved family functioning, social adaptation, and the children's ability to resist negative peer group influences (Muntingh, 1998)

- Insofar as they are all non-custodial at this point, diversion programs appear to be cost effective (Sloth-Nielsen, 2003)

By 2001 the National Directorate of Public Prosecutions estimated that prosecutors were diverting more than 30,000 children per annum away from criminal trials to a range of available programs around the country. Initially, these programs concentrated on the acquisition of basic life skills over a short term of 8 weeks. Thus, the most widely known program, the Youth Empowerment Scheme (YES), functions on a group basis once a week for 8 weeks. YES focuses on the negative effects of crime, gender sensitivity, anger management, and so forth. Chiefly aimed at the large numbers of children charged with minor offences - petty stealing, minor assaults, and damage to property - data showed that the typical diversion candidate was black, 16 or 17 years old, and in trouble for shoplifting, or theft of goods valued at less than R100 (about \$15 USD).

Increasingly, though, instead of the "one size fits all" intervention of the initial (very general) life skills program, the focus shifted to more intensive programs and to specialized youth-justice issues. For example, a dedicated program aimed at children charged with sexual offences was established in 1998. This program is currently used in a variety of different settings, urban and rural, in South African provinces. Subsequently, adventure education and wilderness education programs became linked to the juvenile justice system. The intensive, experiential learning undergone by participants in these programs was shown to be beneficial for "high-risk children" and those involved in more serious offences (Steyn, 2003).

Non-governmental and voluntary efforts to expand access to diversion programs also began to attract community-based initiatives. This was promoted by the scarcity of resources and lack of established organizations in smaller towns outside the main provincial cities. It was also predicated on the need to communicate the effectiveness of diversion (as opposed to formal prosecution) to communities affected by crime. Importantly, community-based programs also link friends and families of high-risk children. The overall proposition is that offending and delinquency are best dealt with 
(in a positive way) within the circle of a child's family and community. This premise underpins the conceptualization of the program we describe further below.

\section{Legal Development in Relation to Diversion}

At the same time that informal arrangements with prosecutors and courts were expanding, authorities were creating a new system for children in conflict with the law. This system started with the appointment of a project committee of the South African Law Reform Commission in 1996. After a three-stage process, with extensive consultation at each stage among lawyers, social work professionals, and government officials, the final report detailing legislative proposals for a new child justice system was released in 2000 (South African Law Commission Report on Juvenile Justice, 2000). This draft legislation was thereafter costed by a team of economists and introduced into Parliament in 2002 (Child Justice Bill 49/2002). This Bill has been extensively debated and reworked by relevant Parliamentary committees. It will be finalized shortly for promulgation. It is expected to be passed in the South African National Assembly during the first term of 2004.

From the outset, the Law Commission proposed that diversion should be regulated by law. The Commission gave three reasons: to ensure coordinated delivery of services in the criminal justice system; to curtail the potential inequality inherent in leaving "decisions to divert" to the goodwill of individual prosecutors; and to protect children. Because diversion programs are intended to be empowering, developmental, and congruent with constitutional rights, the Commission was anxious to prevent unregulated diversion referrals that could be used as a smoke screen for mob justice, for harmful and hazardous practices, or for exploitation. In fact, documented instances of "bad practice" have occurred (e.g., children being humiliatingly stigmatized by being painted and paraded in front of communities).

The Law Commission's Report on Juvenile Justice (2002) detailed legal provisions to regulate and promote the use of diversion. During the course of 2003, the Commission's proposals have been elaborated by Parliament in relation to deliberations on the Child Justice Bill 49/2002. (An entire system of accreditation and registration of programs needs to be established.) The legislation will stipulate that diversion programs aim to achieve certain objectives. The most recent draft of the tabled Bill includes these objectives:

- Foster accountability in the child for the harm caused by the offence

- Meet the needs of the individual child

- Promote reintegration of the child into his or her family and community

- Promote reconciliation between the child and the person and/or community affected by the harm caused

- Prevent stigmatizing of the child

- Prevent adverse consequences that may flow from the child being subjected to the criminal justice system, and prevent the child from having a criminal record 
- Reduce recidivism (clause 46 of the Draft of the Child Justice Bill dated October, 2003) Minimum standards for program presenters are also being incorporated into the body of the legislation. Most relevant among the listed standards (described further below) are the requirements that diversion programs must "promote the dignity and well-being of the child, and the development of his or her sense of self worth and ability to contribute to society" (clause 49.1.cc) and, wherever possible, "impart useful skills" (clause 49.2.a).

Against this background of imminent legislative approval for diversion it remains for us to discuss the potential of community-based music tuition as an element of diversion programming. We shall discuss this potential by focusing next on an existing South African diversion program that offers music tuition to juvenile offenders.

\section{Diversion into Music Education}

We initiated our DIME program as a community collaboration between the University of South Florida (USA), the University of the Western Cape (South Africa), and various organizations within the cities of Tampa and Cape Town. Our DIME program targets children in conflict with the law in these two cities. It aims to empower young offenders by enhancing their capacity and skills, aid them in achieving successful reintegration into the community, and provide them with positive personal, social, and cultural opportunities. The following sections of this paper discuss specific aspects of the South African branch of our DIME program.

\section{Philosophy}

Like countless community music programs established throughout the world, our DIME program is "based on the premise that everyone has the right and the ability to make music" (Veblen and Olsson, 2002, p. 730). Musicality is widely recognized as an innate human intelligence (Gardner, 1983; Elliott, 1995); it is broadly accepted that all children are inherently musical (Scott-Kassner, 1999). Our program does not select children based on musical experience or skill; we accept all referrals without discrimination.

Our DIME program aims to balance (i) children's appreciation of music and (ii) their striving for artistic excellence with (iii) a process that respects the development of the whole child. Our approach is student- centered, not performance-centered. While performing offers valuable benefits for the children that are integral to this program, we place emphasis on the process rather than the product. This praxial orientation (Elliott, 1995) of our program ensures that our children develop their musicianship through making music, rather than learning information about it. This approach aims to achieve self-growth, self-knowledge, and "flow" such that musical challenges and skill are balanced, allowing all children (according to their abilities) to experience engrossment (focus) and musical enjoyment (Elliott 1995; Csikszentmihalyi, 1990). 
A further philosophical tenet of our program is the promotion of respect for diversity and the combating of racism and intolerance. DIME endorses respect for the individual and for differences in musical cultures and preferences. Our program aims to both protect and advance diversity in traditional and contemporary cultures. We promote children's identifications with cultural heritages to foster strong cultural pride and self-respect. Our DIME approach aims to restore dignity for the individual. Furthermore, through intercultural exchanges with students on another continent, the program encourages cultural tolerance and understanding.

\section{Program Design}

When children are referred to our DIME program, they join an African marimba and djembe band. We provide them with regular group music tuition and performing opportunities. As noted above, we design our music-teaching efforts and mentoring to ensure that we facilitate childrens' acquisition of musical skills, their growth in social skills within the group setting, and the translation of these skills and learnings into improved family, school, and social interactions. Like many community music programs, our program recognizes "the participants' social and personal growth" to be "as important as their musical growth" (Veblen and Olsson, 2002, p. 731). The twinning of this project between Cape Town and Tampa provides our children with additional benefits in the form of intercultural exchange, which is facilitated through our international exchange of staff visits and videos that show the groups practicing, performing, and sending words of encouragement to their partner groups.

\section{Instruments}

We selected African marimbas and djembes for three reasons. Firstly, these instruments form part of the cultural heritage of the children. Secondly, a simple, but impressive stage of accomplishment can be achieved in a group setting within a relatively short period, providing the children with a strong sense of accomplishment. Thirdly, the act of hitting the marimbas and djembes requires a fair amount of physical exertion that children appear to find both natural and stress relieving.

\section{Acquisition and Storage of Instruments and Venue Selection}

The construction of a set of large-scale marimbas was commissioned and paid for with funds provided by the USF Collaborative for Children, Families, and Communities. They were hand made by a master marimba craftsman in South Africa. Locally made djembes and hand percussion were also acquired. Providing security for the instruments was a major challenge as the project was to be housed in a severely economically deprived and crime ridden area. Geographical accessibility of the program received high priority, not only to avoid transport issues for the children, but also to promote a sense of ownership of the program. As these instruments would be financially far beyond the reach of these families, the program brought valuable resources into the community. 


\section{Staff Appointments and Training}

Funds from the Open Foundation allowed for the appointment of administrators, researchers, teachers, and mentors and supported the running costs. The music teacher position was given to a local community musician who had a history of both teaching and performing. The choice of music teacher was guided by the intent to build on the strength of the community, tapping the skills of local musicians. With many community artists experiencing little income generation due to high unemployment in South Africa, this program offers a welcome source of part-time income for this teacher. It was also considered important that the teacher be a member of the community to whom the children could relate and with whom they could converse in their native mother tongue.

Recruitment for all other positions took place within the UWC departments of Law and Psychology. Mentors are required to be residents in the geographical area in which the program is housed (although academic semester residency on the university campus is acceptable) and to be of good academic standing. Through service learning, the university students have an invaluable opportunity for working in the broader community and learning through practice in the field. Prior to commencement of the mentoring, training was provided (mainly) by the UWC Department of Psychology. Topics included defining mentoring, relationship building, micro skills, developmental phases, behavior modification, anger management, conflict resolution, and report writing.

\section{The Role of Mentors}

Mentoring involves a more senior, more experienced person guiding a (usually) younger, less experienced person. The mentor's responsibilities involve, among other things, helping mentees set goals, developing their characters, and offering support during the process of their growth toward maturity. The mentor models and cultivates trust, confidence, dependability, and adult-level decision-making skills. Mentoring is based, in part, on social learning theory: the principle that some behaviors are learned by observation and imitation. In other words, some people's behaviors change because they want to be more like the people they identify with and respect.

Mentors in this program accept several responsibilities: attend all practices; visit their assigned children, at their homes after hours; interact informally with their mentees to resolve relationship, family, and peer group problems; engage the children in worthwhile leisure activities; encourage them to avoid negative influences; and assist the children to overcome pressing, school-related problems. Mentors must submit regular reports that describe the emotional well-being of their mentees; their relationships with family, peers, and mentors; their achievement and conduct at school; and any observed or reported changes. (The contents of the reports are, however, not confined to the above issues.) 


\section{Child Referrals}

The children are referred to our program by the National Institute for Crime Prevention and Reintegration of Offenders (NICRO), a non-governmental organization at the forefront of diversion programs in South Africa. In the first stage of this program, social workers were actively involved in making the practical arrangements for the children's attendance in our program. The first group in the pilot program consisted of 14 children, aged 16 and below. These children (a mix of boys and girls) attended various schools in the Khayalitsha community, which is a fast-developing area of formal and squatter-type housing close to the city of Cape Town. (They were referred, though, from a range of courts outside the immediate community.) Pre-program interviews revealed a number of risk factors and problems. According to parental reports, the children were: mixing with the "wrong" crowds; becoming involved in crime; spending too little time at home; showing repeated evidence of anger; failing to maintain satisfying achievement at schoolwork; or experiencing family difficulties. Some children were reported to be unhygienic; others were smoking and drinking alcohol.

\section{Selection of Musical Material}

The children in our diversion programs live in urban situations. Musically speaking, they are very familiar with Western and South African popular music. In our diversion programs, our mentees have a unique opportunity to enrich their cultural lives and experience their musical traditions. (Many urbanized children would not usually have opportunities to hear live performances on traditional African instruments, or play them.) The materials used in our programs include both traditional and contemporary music for African marimbas and djembes. We aim to enable our mentees to preserve and construct their cultural and personal identities by encouraging our children to connect with diverse cultures, celebrate old traditions, and engage in new forms of musical creativity, improvisation, and composition

\section{Pilot Project}

A pilot project was established in 2001 to launch the start of our program, which has (over the ensuing years) incorporated additional groups of children diverted from the criminal justice system. The pilot phase served for the developing of efficient teaching systems and for conducting an initial research project. A marimba concert with performances by a local community group (of which the music teacher was a member) was held to launch the program. The concert had several aspects: children and their parents were able to witness the musical medium in which the children would become engaged; important public figures encouraged the children; program information was provided; and research-consent forms were signed. The matching of mentors to mentees also took place at this event.

\section{Teaching Pedagogy}

The teaching strategy focuses on active participation: students are engaged in discovering, performing, and improvising. (Learning facts about music is not the 
goal.) In our experience, the children display intense delight and the emergence of a vigorous self-confidence. Generally, behavior management is not an issue, as the children are actively engaged and are motivated to participate through their immediate enjoyment and their vision of self-improvement and achievement. Teachers use some traditional teaching styles, including repeated demonstrations and imitation. Oral instruction often takes the form of vocal sounds that reinforce rhythms and, very occasionally, verbal explanations. No technology, audiovisual aids, textbooks, notation, or other learning media are used. Our programs are non-literacy based, reflecting the aural tradition of music education in ethnic South African population groups. The underlying premise of our program is to offer respect for the origins and intents of these specific musical practices. Traditionally, the style of music being taught in the program was not notated; the underlying principal is one of improvisation. Learners are guided informally in understanding the harmonies, melodic structures, and polyphonic rhythms of the music. Demonstration-based teaching has proven to be an important alternative to speech-based instruction. For one thing, this teaching mode is extremely flexible. Initially, the children learn through rote imitation; soon, however, they are guided to develop their musical ideas through improvisations. Our style of teaching aims to promote our students' sense of ownership of their materials.

The intricate and complex nature of creating music in a group setting allows the children to develop in various facets. Our program is an example of the model described by Veblen and Olsson where ...the individual has freedom within the group to explore new roles...The individual has the ability to move through a variety of roles, from observer, to participant, to shaper and creator, finding different ways to participate .Identity and self-expression are potent factors within the collective; belonging, coding, immigration, assimilation, and globalization are all played out through musical communities. (Veblen and Olsson, 2002, p. 731).

Although in group settings, students periodically receive individual attention. Other students are free to observe the interaction, practice their own parts, or teach other students. The interaction is characteristically one of a collaborative nature between the learner and instructor. Individual expression and improvisation is encouraged, which in turn promotes artistic innovation and originality. Although the music sessions are initiated and guided by the music teacher, teaching is something that occurs in a wave model. Students learn their own part and then teach it to another student. Teaching is one of the most successful ways to reinforce learning. Students are encouraged to learn several, if not all, of the musical parts on various marimbas, djembes, and hand percussion. This encourages students to understand varying musical elements. Being able to perform several different musical parts develops the children's flexibility and a better sense of making music their own.

Emphasis on Personal Fulfillment Social Intervention Through Musical Socialization Personal fulfillment and self-realization are important steps towards a 
child's social integration. Musical experiences can change the moods and influence the social behavior of these juvenile offenders. Our program offers the opportunity for these children to break away from possible negative states that influence their behavior. Strong emphasis is placed on social intervention. Association with delinquent peers is one of the powerful predictors of juvenile delinquency. These groups tend to encourage delinquency and provide opportunities for such acts (Dishion \& Patterson, 1997). "An association with delinquent peers is a powerful predictor of juvenile delinquency" (Gold and Petrinio, 1986, p. 36). Through our program, juvenile offenders have the opportunity to engage in healthy activities that create diversions from crime. Our program invariably reduces the possibility of children becoming involved in delinquent acts by reducing a child's association with delinquent peers. Furthermore, our students are brought into a social group that is focused on achieving positive social behavior. The supportive nature of those relationships with non-delinquent peers is significant: "adolescents and young adults with conduct disturbances who form close relationships with others who do not have such problems are much more likely to 'grow out' of their conduct disturbances." (Nolen-Hoeksema, 2001 p. 453). As a microcosm of society, our program provides children with the opportunity to meet peers and to develop friendships. The group context offers: learning to communicate more effectively; expressing emotions; managing anger; and resolving conflicts. An adolescent developing these skills is less susceptible to negative emotional states and generally maintains healthy relationships with others.

Musical socialization provides children with the opportunity to develop essential life skills. Ensemble playing requires the following: sensitivity; listening to others; sensitive interaction; working towards a common musical goal; co-operation; and responsibility towards others. Slobin (1993, p. 60) describes this situation as a "jointly imagined world that arises from a set of separate strivings temporarily fused at a moment of common musical purpose." Every note played fits into the musical structure created by the group. And listening for the placement of each note is a complex task requiring acute attention to and cooperation with the actions of others. Having the opportunity for these kinds of practical experiences may be critical issues for children involved in conflict with the law and with society. The children begin to put aside their personal problems and relationship issues to perform successfully within the group. Our program promotes the acceptance and equality of all players. It also aims to convey tolerance, empathy, understanding, and sensitivity. The participants experience what Veblen and Olsson (2002, p. 731) describe as both "individual responsibility to the group and a reciprocal sense of group responsibility to the individual." The children acquire important social skills by working as successful members of a group. The students listen to others, do not show off, do not interrupt the teacher, and become one player working for the emergence of the "whole" musical work. They develop: concentration; singing and moving from performing complex materials; and improvisatory and creative skills. These skills have applications in many other aspects of their lives. 


\section{Performances}

A risk factor associated with offending behavior is poor self-esteem (Dishion \& Pattersen, 1997; Nolen- Hoeksema, 2001). An adolescent with positive self-esteem is less likely to join delinquent peers, give in to peer pressure, be aggressive, and/or use illicit drugs. Performances are a significant feature in our project. They showcase a student's achievements and promote motivational goals. Performances offer children the opportunity for positive feedback and, in turn, students develop a healthy sense of self-worth and pride. Groups perform musical works with a challenge level equal to their own skill level. After a month to three months of training, groups of students are able to perform a concert. The achievement and success of the group is experienced both individually and collectively. This leads to a student's enhanced self-esteem and confidence in interacting with the public.

\section{Global Awareness and Intercultural Connections Through Technology}

The influences of globalization in our program are evident in two distinct areas. Firstly, Western influences on traditional music cultures can be detected. Secondly, the program fosters awareness of globalization through international collaborations and connections that are integral to our program's existence. With the aid of technology, our program incorporates networking and collaborations between staff and children across cultures and continents. Video footage of practices, performances, and interviews is sent to partner groups of children in similar circumstances across the globe. Parental permission is acquired for the filming and use of materials that do not involve publication or public distribution. Students observe the musical progress of partner groups and listen to other children describing themselves (with details such as their favorite food and activities). They encourage the partner groups to "pull up their socks;" to "make right choices;" and to "persevere in the musical learning." As one South African offender in our DIME program said to American partners: "I wanted to leave a message with you guys. You must carry on with your music, you must stop doing bad things, be yourself." Our program fosters intercultural and interpersonal acceptance and understanding.

\section{Implementing the Evaluation Component}

Since the evaluation of our program was a key objective, the research component was built in at the outset. Prior to our program's commencement, staff from the UWC Psychology Department interviewed the participating children and their parents. The senior researchers at UWC and USF developed the interview and report schedule with valuable staff inputs from the psychology departments. On-going reports and follow-up interviews provided data for the research evaluation.

\section{Results}

\section{Musical Development}

The children progressed rapidly in developing musical skills that were not present at the start of our program. Assessment was done by our program's music teacher and by collaborators in Tampa, who either traveled to Cape Town to observe in person or 
analyzed video footage. By learning to play these instruments, the children developed a musical understanding that was evident in their use of pitch, rhythm, tone colors, dynamic levels, harmonic and polyphonic structure, and form. They learnt the skills to perform on these instruments and became independent musicians within a group, capable of performing successfully in public. Listening skills were developed as they co-operated within the group and produced desired musical results. Their creative skills emerged through improvisation. Furthermore, they succeeded in teaching musical skills to other members of the group.

\section{Reintegration Into Society: Reports by Parents}

A qualitative study revealed, during parent interviews, that several positive developments emerged. Family relationships improved as certain students began: asking permission before going out; assisting regularly with household chores; not staying out late; demonstrating increased respect; and acting responsibly. One parent reported: "He's being more honest and I love the project and I am grateful to you guys." Generally, the children demonstrated improved dispositions. Parents embraced the marimba bands because they symbolize the celebration of African heritage and acceptance of cultural values. Parents were positive about their children making music rather than shoplifting (as they were previously prone to do after hours). They reported that their children's attitudes towards schooling were generally positive. Parents were pleased to observe their children becoming involved in teaching the younger children in the community. One parent described his son's transformation after joining the program:

Ever since he joined the project he has changed. There's a big, vast difference. He was a little, rude boy but now he's a very good boy. Now he's helping at home. Before, he used to wake up very early, he's roaming the streets, and then you would see him late at night. But not any more, he's always busy... He likes this music. I can say he's living this music.

\section{Reintegration Into Society: Reports by Mentors}

Mentor reports indicated that all the young offenders in the program appeared to experience a positive response to the mentoring relationship: "I observed the impact that mentoring and role modeling, in conjunction with music, has on encouraging these kids." Initial caution on part of students towards their mentors gave way to growing openness and trust. Mentor reports indicated that they seemed to have had good relations with their mentees. The mentees appreciated having a confidant who was willing to listen and provide an accepting space within which to share concerns, fears, and sorrows. Mentors reported being aware that the children's parents felt more confident that their children were in safe hands when attending practices with mentors.

The overall impression of the students who acted as mentors was positive. They were excited with traveling opportunities offered by the program for performances, 
learning more about music, improving their own communication skills, and learning to work with at-risk children through practical experience. As one mentor expressed: "I am always there for them, to help them. I guide them, to help them go through whatever difficulties they face as teenagers."

\section{Reintegration Into Society: Reports by Children}

Analysis of the mentoring reports and follow-up interviews suggests that the children found playing marimbas to be a positive experience associated with exhilaration, a sense of mastery, and the discovery of musical aptitude (Sloth-Nielsen \& Mathiti, 2002). The children described these experiences as: "enjoyment," "happiness," and "excitement." The children felt that playing the marimbas provided them with a sense of purpose. Most felt they were encouraged to stay out of trouble by being engaged in making music rather than crime.

A striking finding from the interviews is the degree to which the children appreciated our program. It took them "away from the streets." When requested to elaborate, one student remarked that: "There are bad things happening on the street. children of my age are being killed. There are other things going on. some guys are using drugs and committing robbery."

The training sessions were possibly experienced as a safe space that enhanced a sense of security. Despite the fact that English is not their first language, the opinions of the children about our program are clearly expressed. In the words of one girl: "I think it's good for me, it is giving me a better chance of playing the marimba. Marimba could be my future. One day I could become a very good musician. And it distance me away from many things because by the time I play marimba, there are many bad things outside that are happening and I am being avoided by it."

Acquiring skills in playing the marimbas helped the children to experience a sense of achievement. It is clear from performances that they all reached acceptable standards of practice. One child remarked (in an interview) that he felt he could compose his own marimba music. This comment suggested that his sense of accomplishment and self-perception was greatly improved. While all the students achieved a community performance level skill, a few are seriously considering a music career. One of the boys remarked that: "Playing marimbas actually changed me because I fell in love with the music. Whenever I thought about the drums, I felt I could be a musician." This suggests that the mastery of a new skill, namely, playing the marimbas, increased his self-esteem and offered him a vision of having a future. The early South African groups have not graduated from the program. They refuse to leave, as the program has become an integral part of their lives. They continue to practice, perform, and volunteer their services as teachers of the incoming groups. As one student from the first group said: "I like my music very much. I like to practice a lot. I like to teach the young people. Most of my time I spend doing that." 
Regarding the mentoring, one of the children mentioned that her attention and concentration span had increased due to the fact that she could confide in someone else. She described how the emotional availability and advice of her mentor provided a sense of stability and stress relief that helped her feel more at ease with her schoolwork. Furthermore, the practice sessions and performances improved family communication. The following remark illustrates this: "I constantly think about the songs. My mother asks me about the practice. I tell her and sometimes demonstrate. She laughs when I show her." Recently, students from the original pilot phase (now having reached up to age 18) announced that they were ready to perform on a professional level for the tourist industry and were seeking assistance in acquiring their own set of instruments in order to embark on careers. The possible impact of these children earning an income in a country of massive unemployment is highly significant and has the potential to impact individuals, families, and communities.

\section{Evaluation of the program}

\section{The Development of Musical Skill}

Children referred to our program are observed to develop significant musicianship. They successfully learn to play new musical parts, to perform coherently within a group, and to improvise. The groups receive invitations to perform at a variety of events and are able to do so successfully after being with our program for a few months. These skills are an important part of capacity building, setting these children apart from their peers, giving them specific skills that are beneficial in terms of healthy forms of recreation, and possible income-generation. The self-realization achieved through making music is evident as the children express their enjoyment and sense of fulfillment.

\section{Compliance and Recidivism Rate}

In addition to the extensive subjective indicators of the positive impact music making has on offending behavior, a few objective indicators were noted. This included compliance rates of $91 \%$ for the pilot group, thus meaning that a significant number of children complied with program requirements (attendance at practices and performances). The recidivism rate for the pilot group in the 6 months post-program was $9.09 \%$. In the second six months, this dropped to $0 \%$, with no repeat offences committed (Mathiti, 2002).

\section{The Potential of Music Engagement as a Reintegrative Tool}

The researchers observed that making music has the potential to influence and change the moods of the children who enter our program. They come to us in a state of conflict with the law, and, by inference, possibly in conflict with their community and families. The shared enjoyments the children experience from playing the marimbas have triggered positive emotions such as delight, elation, pleasure, and contentment. Due to the therapeutic effects on the psychological state of the children, making music provides a rehabilitative tool and contributes to the discontinuation of negative behaviors and strengthens positive behaviors. A positive emotional state can 
be an antidote to juvenile delinquency, particularly if it permeates significant areas such as school and home. In addition, the musical skills acquired by the children allow an opportunity for non-verbal self-expression and communication, providing an expressive and creative outlet.

The evaluators took particular note of students' remarks stating they constantly think about the marimbas. For them, being a good player requires "focus on the music and not on negative things such as crimes and dagga" (the latter is a slang term for marijuana). Therefore, making music played a significant part in changing their thought patterns: their minds were immersed in music. According to cognitive theories, positive thought content is a necessary condition for productive, functional conduct (Nolen-Hoehsema, 2001). This could be a mechanism that enhances the positive impact of our program, in which negative, maladaptive, and dysfunctional thoughts are either displaced or substantially reduced. Whereas thoughts about crime influences one to pay attention to criminal opportunities, thoughts about making music implies that less attention is paid to those opportunities. From a cognitive perspective, this is a significant change that can serve as a basis for a paradigm shift. In other words, cognitive restructuring is a significant element for individual and community integration.

By reducing the likelihood of the association with delinquent peers, our program is seen to invariably reduce the possibility of children becoming involved in delinquent activities. As a microcosm of society, our program provides opportunities for meeting peers and developing friendships. The group context allows students to communicate more effectively, express emotions, manage anger, and resolve conflict. An adolescent who is developing these skills is less susceptible to negative emotional states and more likely to maintain healthy relationships with others. The children are able to support each other in their resolve to desist offending behavior.

Our program was successful in aiding the children to connect with their families, communities, and culture. The fact that parents regularly attend concerts is a positive development, indeed. This suggests that our program, in some families, contributed to improved communications. Those children, whose parents encourage them to share their experiences with them, often interpret the encouragement as a sign of parental interest, care, and love. Perceptions of parental interest and support can lead to feelings of self- worth and nurture, feelings that are integral to positive adolescent psychosocial development (Nolen- Hoeksema, 2001). Making music with traditional links to their cultural heritage contributed to the construction of the children's identity and self-pride. Teaching children music that is part of their cultural heritage means that the music becomes an important socially integrative tool. The use of the children's mother tongue, Xhosa, in practice sessions, concerts, speeches, some interviews, and so forth, further reinforced a sense of regard and respect for their own cultural identities. 
Another significance of our marimba program lays in offering children to discover and use their bodies in new ways. Playing the marimbas necessitates vigorous use of the upper body, dexterity in gross motor movement in the upper limbs, and skilled coordination. The children often respond to the sounds (while playing the instruments) with spontaneous movement and dance. The experience of combining singing, performing on instruments, and dancing is a new way of using the body for the children. This form of physical activity appears to provide a valuable form of stress release.

Involvement in our program enabled children to experiment with new self-images. Discovering their ability to learn to play music as unique, essential, and contributing members of a group, allows the children to positively see themselves as team workers and active participants in an enjoyable and encouraging social pursuit. Their ability to succeed in a performance contributes to a sense of mastery. The rigorous demands for cooperation and sensitivity in the group music setting assists the children in developing social skills and encourages pro-social behavior modification. Through the performances, the children are able to transform old self-representations. They are extremely proud of their newfound abilities and eager to showcase their skills to an audience. The performances elicit positive responses from the audience, and have a positive impact on the children's self-perception and feelings of self-efficacy. An appreciative audience shows the children that they can have a positive influence on the lives of others through music. Whereas their self- evaluations were initially negative due to (among others) offending behavior resulting in negative public perception, the enthusiastic responses from parents and community members in the audience deconstructs such evaluations. Therefore, our conclusion is that music can play a crucial role in psychological reintegration and the development of self-realization.

\section{Mentoring as an Aid to Successful Reintegration}

Even though mentoring has long been an important human concern, and has a significant place in traditional African culture, the measurement of the efficacy of mentoring programs in the scientific community in South Africa is a relatively recent phenomenon (Jekielek et al., 2002, Herrera et al., 2000). The research team concluded the following after examining the potential of mentoring as a reintegrative tool. The mentoring component of our program formed an essential and effective means for children to connect their musical experience in the program with the outer world. It provided the opportunity for children to share their concerns and problems, giving them a positive model for community living. Parents found reassurance in the knowledge that their children had mentor supervision at practices and performances. The researchers recognized that our mentoring programs need time for the development and growth of relationships. In addition, it cannot be assumed that mentors, even after initial training, would have the know-how to fulfill all the functions required of them. Challenging situations can arise and the mentors need both ongoing training and access to support. 


\section{The Benefits of Wider Exposure to Society and to Intercultural Exchange}

Evaluations concluded that our program plays an integrative role by providing children with the opportunity to learn more about their social world. Through group participation, they have the opportunity to meet many caring and encouraging people. This includes administrative staff, teachers and mentors from the program, prominent public figures, and a wide range of people who attended their performances. Most importantly, they develop a positive social and peer group identity. They visit new places (that would normally be out of reach) and are granted an informal education from invaluable experience and exposure.

The children benefited from experiencing intercultural communication with children engaged in similar pursuits in other parts of the world. This component led them to view the world differently. While their family and social circle may be presenting problems, the children are able to experience a world inhabited by caring, positive people. This new sense of the world as a safe space is crucial in the integration (at both individual and communal levels) of any person. Through the exchange of video material, the children in our program enter into the lives and experiences of their partner groups. They are able to watch film footage of each other practicing and performing and this motivates their own musical development. They describe their own cultures and give messages of encouragement to one another to improve both their music and their lives. Peer motivation from another part of the globe develops a healthy lifestyle is potentially a powerful incentive. Technology provides the children with an invaluable intercultural connection that promotes acceptance of and respect for diversity and cultural differences.

\section{Conclusion}

On-going qualitative research is indicating the value of music-making programs for children in conflict with the law as they provide students a healthy, enjoyable diversion from crime. Through developing their musicianship, children achieve self-realization. Besides capacity building, our program enables children to discover (or rediscover) their intense enjoyment of music and a strong sense of self-fulfillment. Particular success is noted with percussion instruments because the students can acquire early success, thus leading to feelings of accomplishment and improved self-image. Performing on the large African marimbas and djembes involves healthy, vigorous, physical activity and appears to relieve stress. While the children initially have no choice regarding their referral to our program, the music making experience becomes self- motivational. There are strong indications that our program has positive influences on individual, family, and academic life. Results point towards the importance of independent mentoring to assist the children with the reintegrative processes through providing a positive role model, advice-giving, and positive reinforcement. Also the exposure to wider social circles and to intercultural communication, through international partnerships, offers the children new perspectives on society, the global community, and their place in the world. 
The vision of our program is to take children on a road of lifelong musical enjoyment, enrichment, and learning. Further benefits may lie in possible economic upliftment through the long-term use of these skills, whether applied directly in the field of music or in other fields. The potential to generate income is very significant in a society that presents large-scale unemployment (currently over $40 \%$ in South Africa). The thriving tourist industry in South Africa offers a real source of full- or part-time income for traditional musicians.

Our program aims to develop its focus on the empowerment of children. Potentially, the disadvantages children in conflict face with the law may be significantly overcome by the benefits of diversion programs that provide them with capacity building and social skills. By providing a healthy diversion from crime, our program aims to decrease involvement in delinquent behavior, involvement with gangs and drugs, and future encounters with the juvenile justice system.

Future goals for our program will be to investigate implications of the research on resilience and protective factors for enhancement of the well being of children, their families, and their communities. Internal protective factors are being provided through improving the children's ability to: achieve and maintain an inner calm; be sensitive to others; maintain a sense of humor; improve self-image; manage conflict; make decisions and healthy choices; function efficiently within a group; and lower stress reactivity. External protective factors offer a robust after-school program by developing strong connections with positive role models and encouraging positive attitudes and improved relationships in school and family. Research on external protective factors connected with positive outcomes is particularly important as communities seek to support healthy child and family development. Future studies will investigate improvement in academic performance. Evaluation of the long-term impact of reducing juvenile crime and recidivism will be an important feature in the future of our program.

Further expansion of our program may provide technological training and resources for the children by using the Internet to communicate with the partner groups across the world. Future research should observe the long-term political and socioeconomic implications of implementing music programs for court- adjudicated children. It is anticipated that additional funds may be solicited in order to increase the number of children that can be incorporated into our program, eventually making it available for all children referred to diversion programs in Cape Town and the partner city of Tampa. Our program will continue its initial aim to be multicultural, including musical instruments and styles that meet the needs of the cultures within the diverse communities. Furthermore, our program will hope to eventually expand, including other performing arts, such as dance and theatre. Our program will continue its aim to provide these children with skills that would not only divert them from crime, but could potentially lead them to opportunities for further study and eventual income 
generation. Furthermore, it will pursue its aim to develop personal and social skills that would lead to the children's successful reintegration into society.

The established model has the potential to be replicated across the world and to incorporate additional collaborations. It promotes ideals that are cherished internationally, such as: developing a strong, dynamic, and vibrant artistic life for children; promoting accessibility to the arts; offering training in the arts and resources for creating and distributing the arts; supporting the pursuit of artistic excellence; and preserving cultural heritage while encouraging intercultural understanding and tolerance. Obtaining measurable success in programs such as this would likely create a more positive climate for youth development efforts, family support, and community upliftment programs. 


\section{References}

Csikszentmihalyi, M. (1990). Flow: The psychology of optimal experience. New York: Harper and Row.

Dishion, T.J. \& Patterson, G.R. (1997). The thinking and severity of antisocial behaviour: Three hypotheses within an ecological framework. In D.M. Stoff, J. Breiling \& J.D. Maser (Eds.), Handbook of antisocial personality disorder (pp. 205-217). New York: Wiley.

Elliott, D. J. (1995) Music matters: A new philosophy of music education. New York. Oxford University Press.

Gold, M. \& Petrino, R. J. (1980). (1986). Delinquent behaviour in adolescence. In J. Adelson (Ed.)Handbook of adolescent psychology. New York: Wiley.

Gardner H. (1983). Frames of mind: The theory of multiple intelligences. New York: Basic Books Inc.

Herrera, C.; Sipe, C.; McClanahan, W. S. with Arbreton, A. J A. \& Pepper, S. A. (2000). Mentoring school age children: Relationship development in community-based and school-based programs. The National Mentoring Partnership Public/Private Ventures. Washington, D. C.: Commissioned By the National Mentoring Partnership and the US Dept. of Education.

Jekielek, S. M.; Moore, K. A.; Hair, E. C. \& Scarupa, H. J. (2002). Mentoring: A promising strategy for youth development. Child Trends, Washington, D.C.: Available at http://www.childtrends.org/PDF/MentoringBrief2002.pdf.

Mathiti, V. (2002). An evaluation of a diversion into music education (DIME) programme for at-risk youth: Implications for programme development. Paper presented at the 14th International congress on Child Abuse and Neglect. Denver, Colorado.

Muntingh L. (1998). A longitudinal study of diversion. NICRO. Cape Town.

Nolen-Hoeksema, S. (2001). Abnormal psychology (2nd. Ed.). New York:

McGraw-Hill.

Scott-Kassner, C. (1992). Research on music in early childhood. In: R. Colwell (Ed.), Handbook of research on music teaching and learning (pp. 633-650). New York: Schirmer Books.

Sloth-Nielsen J. (2001). The influence of international law on juvenile justice reform in South Africa.Unpublished masters thesis, University of the Western Cape, Cape Town, South Africa.

Sloth-Nielsen J. (2003). The business of child justice In J. Burchell \& E. Erasmus (Eds.), Criminal justice in a new society. Cape Town: Juta \& Co, Ltd. Sloth-Nielsen, J. \& Mathiti, V. (2002). DIME (Diversion into music education). Report submitted to the Open Society Foundation for South Africa. Available atwww.osf.org.za/File

Uploads/docs/MentoringProgrammesforYouth18June2002.pdf

Slobin, M. (1993). Subcultural sounds: Micromusics of the West. Hanover, NH: Wesleyan University Press.

South African Law Commission Report on Juvenile Justice. (2000). South African 
Law Commission Child Justice Bill (2002). South African Law Commission Report on Juvenile Justice. (2002). South African Law Commission Draft of the Child Justice Bill. (2003).

Veblen K. \& Olsson, B. (2002) Community music: Toward an international overview. In R. Colwell \& C. Richardson (Eds.). The new handbook of research on music teaching and learning (pp.703-756). New York: Oxford University Press.

Sheila Woodward is Assistant Professor of Music Education at the University of South Florida, Tampa. e-mail: woodward@arts.usf.edu 